\title{
Mycorrhizal Status of Natural Stands of Pterocarpus erinaceus Poir. (Fabaceae) in Sudanian and Guinean Zones of West Africa
}

\author{
Pyoabalo ALABA ${ }^{1 *}$, Komla Elikplim ABOTSI ${ }^{1}$, Kossi ADJONOU ${ }^{1}$, \\ Kossi Novinyo SEGLA ${ }^{1}$, Adzo Dzifa KOKUTSE ${ }^{1}$ and Kouami KOKOU ${ }^{1}$
}

${ }^{1}$ Forest Research Laborotory, University of Lomé, 01BP1515, Lomé, Togo.

Authors' contributions

This work was carried out in collaboration among all authors. Authors AP, KEA and KK. Designed the study authors AP, KEA. Performed the statistical analysis authors AP, KK wrote the protocol. All authors wrote the first draft of the manuscript. Authors AP, KEA, KK. managed the analyses of the study. Authors AP, KEA managed the literature searches. All authors read and approved the final manuscript

Article Information

DOI: $10.9734 / A R R B / 2021 / v 36 i 630392$

Editor(s):

(1) Dr Paola Angelini, University of Perugia, Italy.

(2) Dr. Manikant Tripathi, Dr. Ram Manohar Lohia Avadh University, Faizabad, India.

Reviewers:

(1) Mariana Luiza de Oliveira Santos Ramos, Federal University of Pernambuco, Brazil.

(2) Angel Carlos Bassols Ricardez, Universidad Nacional Autonoma De Mexico, Mexico.

Complete Peer review History: http://www.sdiarticle4.com/review-history/70316

Original Research Article

Received 27 April 2021

Accepted 01 July 2021

Published 06 July 2021

\section{ABSTRACT}

Background and Aims: The sylviculture of Pterocarpus erinaceus is still in its infancy due to lack of information on its biology. The aim of this study is to investigate its mycorrhizal status in order to better address its sylviculture.

Place and Duration of Study: The study was performed on the field from May 2019 to December 2020 and data were analyzed at the laboratory from January to March 2021.

Methodology: The frequency and intensity of mycorrhization were determined under a microscope after staining with trypan blue of fine roots collected at a depth of $20 \mathrm{~cm}$ under adult plants at 5 sites, 3 in the Guinean zone and 2 in the Sudanian zone in Togo. The spore density was obtained on soil samples taken at the same depth under the same trees.

Results: Results indicate, without significant differences $(P$ value $=0.166)$ among sites, and show that $P$. erinaceus is frequently mycorrhized (88\% to $94 \%)$. However, there were significant 
differences ( $P$ value $=0.001)$ in spore densities between sites located in the Sudanian zone (16.53 \pm 1.25 and $10.66 \pm 0.71$ spores per gram of soil - SPGS - respectively for the Fazao-Malfakassa and Oti-Kéran-Mandouri) and those located in the Guinean zone (4.54 $\pm 0.3,2.93 \pm 0.43$ and $3.76 \pm$ 1.01 SPGS respectively at Abdoulaye, Hahomegbe and Togodo). There are significant differences between mycorrhization intensities Togodo which has a mycorhization intensity of $33.52 \pm 2.54$ and other sites. The redundancy analysis carried out by taking into account substrates' chemical characteristics shows that spore density remains low when phosphorus and nitrogen are important in the rhizosphere whereas the intensity of mycorhizations is low when $\mathrm{PH}_{\mathrm{KCl}}$ is high.

Conclusion: This study provided evidence of mycorrhizal symbiosis in Pterocarpus erinaceus whether in the Sudanian or Guinean zone. Chemical quality of the growing substrate has an influence on parameters of mychorization. Further studies should therefore allow an assessment of the degree of dependence of this species with respect to the possible benefits associated with this symbiosis.

Keywords: Pterocarpus erinaceus; mycorrhization intensity; mycorrhization frequency; sporulation; Togo.

\section{INTRODUCTION}

The excessive exploitation of forest species is one of the main causes of the loss of biodiversity and forest cover in tropical environments [1]. This over-exploitation of forests, combined with the devastating effects of wildfires, leads to the disappearance of certain high economic value species, such as Pterocarpus erinaceus, commonly known as "vène" wood. This species, whose natural range is limited to West Africa $[2,3]$, is facing difficulties in maintaining stable and viable populations because of its many uses [3-7]. Overuse of natural stands of $P$. erinaceus throughout West Africa [8,9] impacts its regeneration and consequently its survival [10]. In order to compensate for the strong pressure on this species, it becomes urgent, even vital, to increase its production through silviculture and/or efficient and rational management. To achieve this, it is essential to understand the biology of the species and to remove all the ambiguities that have so far hindered its silviculture [11,12]. The main difficulties associated with the silviculture of $P$. erinaceus include the poor growth of young seedlings (from seedlings) and their generally creeping lifeform in the juvenile state $[13,14]$.

While the importance of mycorrhizae in plant development is definitely accepted [15-17], the mycorrhizal status of many tropical forest species such as $P$. erinaceus remains almost unknown. Indeed, several studies have revealed that among the functional groups including soil microflora, there are mycorrhizal fungi that colonize the majority of plant species with beneficial effects applicable to agriculture, horticulture and forestry [18]. Le Tacon [15] shows that in reforestation sites without propagules such as treeless areas, mine spoil, etc., non-mycorrhized plants do not develop and most of the time die. This work also argues that the success of a forest plantation is totally dependent on the mycorrhizae associated with the seedlings from the original nursery.

Despite the mixed results of the work done on the silviculture of $P$. erinaceus, little attention has been paid to the biology of the species and the potential symbiotic relationships, especially with mycorrhizal fungi, that the species may have in its natural environment, which could provide an opportunity for domestication of the species. In fact, in tropical Africa, as in Togo for example, studies on mycorrhizal symbiosis and its consideration in the production techniques of seedlings for reforestation in view of the domestication of certain valuable species remain very limited. This domestication should allow diversification of the reforested species and promotion of native biodiversity by avoiding the exclusive importance given to the exotic species in reforestation programs.

The general objective of this study is to contribute to the mastery of $P$. erinaceus silviculture through a better knowledge of its mycorrhizal status in natural stands. Specifically, the aim is to (i) evaluate the degree of sporulation of soils collected under natural stands of $P$. erinaceus, and (ii) evaluate the mycorrhizal colonization of $P$. erinaceus roots in its natural environments. 


\section{METHODOLOGY}

\subsection{Study Area}

In order to highlight the mycorrhizal symbiotic relationships in $P$. erinaceus, soil and fine root samples of the species were collected at 5 sites spread over the whole Togolese territory in order to covering the ecological heterogeneity of the species' habitat in the country [3]. Three sites in the Guinean zone (Togodo national park ecological zone V -; Hahomegbe Community Forest and Abdoulaye Wildlife Reserve ecological zone III -); and two sites in the Sudanian zone (Fazao-Malfakassa National Park (FMNP) - ecological zone II - and Oti-KéranMandouri national park (OKM) - ecological zone I -) (Fig. 1). Ecological Zone I correspond to the plains in the extreme north of the country. It has a Sudanian type climate with annual rainfall varying between 800 and $1000 \mathrm{~mm} /$ year. The predominant vegetation is the Sudanese savannah. In this zone, there are a few patches of dense dry forests and gallery forests along the waterways. Ecological zone II corresponds to the northern part of the Togo Mountains, where the vegetation consists of a mosaic of dry mountain forests and gallery forests. The climate in this zone is Sudano-Guinean with an average rainfall (1200-1600 mm/year). With a tropical Guinean climate and a rainfall of 1000-1500 mm/year, ecological zone III (central plains) is covered essentially by a Guinean savanna. There are pockets of semi-deciduous and dense dry forest. Ecological zone IV corresponds to the part of Togo with semi-deciduous forests. The rainfall sometimes exceeds $1600 \mathrm{~mm} /$ year. Ecological zone $\mathrm{V}$ has a dry sub-equatorial climate, with 800-1200 mm/year. It is covered by a mosaic of savannahs, dense semi-deciduous and typical wetland ecosystems such as mangroves, flooded savannahs and flooded grasslands [19]. The sampling sites are located as shown on Fig. 1.

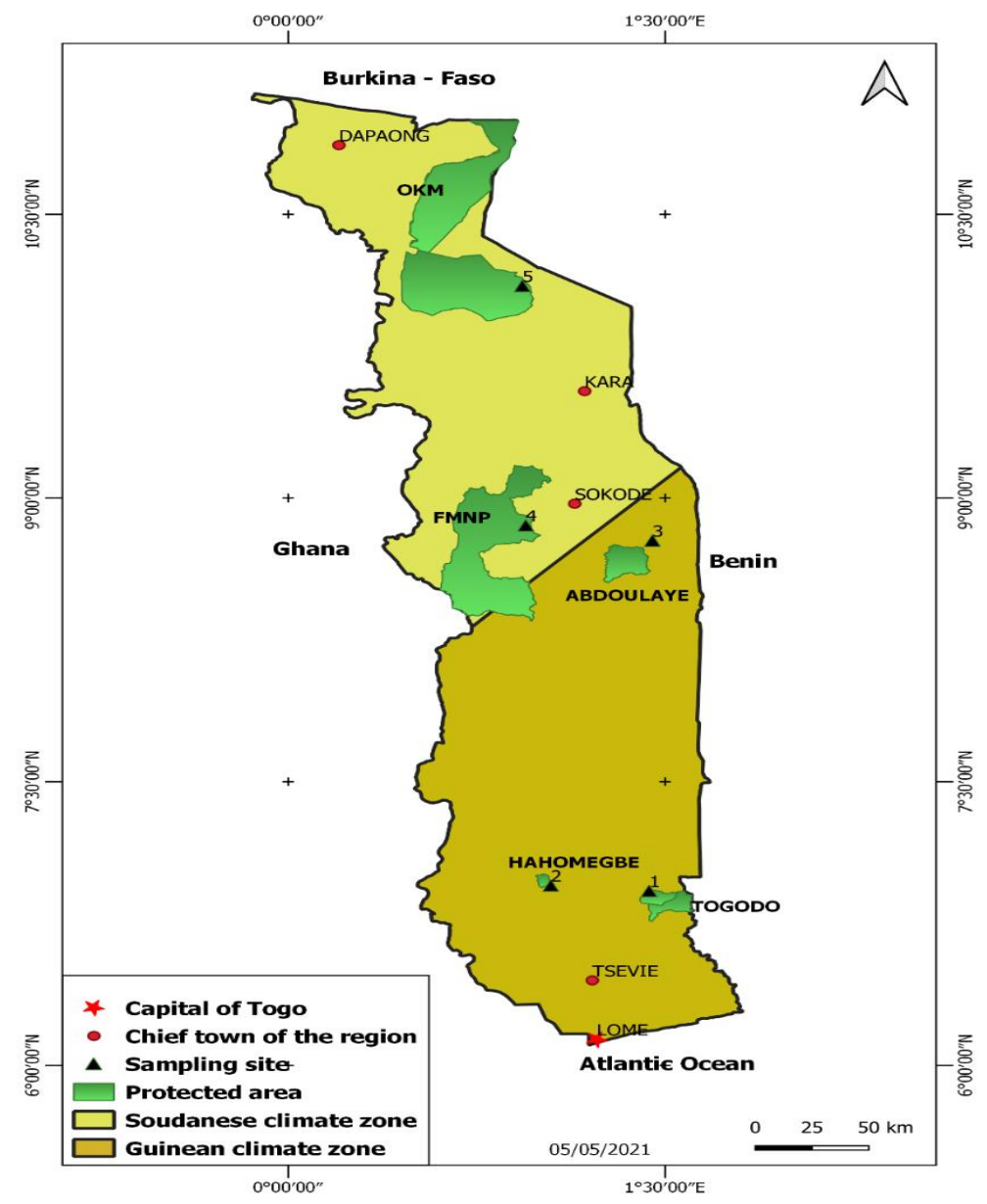

Fig. 1. Localization of soil and fine roots of $P$. erinaceus sampling sites in Togo ${ }^{*}$ OKM: Oti-Keran-Mandouri national park; FMNP: Fazao-Malfakassa National Park 


\subsection{Characteristics of Sampled Soils}

The chemical composition of the soil from each site was determined at the reference soil laboratory in the "Institut Togolais de Recherche Agronomique" (ITRA) (Table 1).

\subsection{Methodology}

\subsubsection{Collection of soil and root samples}

Fine root and soil samples were collected from under adult $P$. erinaceus plants at all five sites. Sampling was done by taking two $250 \mathrm{~g}$ soil samples with a probe from a depth of about 20 $\mathrm{cm}$ at two points on either side of the tree within a 1-meter radius. Soil collected from under the same tree at two symmetrical points was used to create a composite sample for the tree. At each site, 4 adult $P$. erinaceus trees were sampled. The sampled soil was dried at room temperature for two days and stored in a refrigerator.

Fine root sampling was done at the same time as soil sampling following the same procedure. The labeled root samples were stored in a refrigerator at $4^{\circ} \mathrm{C}$.

\subsubsection{Estimation of spore density of mycorrhizal fungi}

Spores were isolated using the wet sieving technique of Gerdemann and Nicolson [20]. Thus, $100 \mathrm{~g}$ of each soil sample was washed in $500 \mathrm{ml}$ of tap water. To promote homogenization, the mixture was shaken for a long time and then allowed to stand for 1 minute. The suspension is passed through a series of $500 \mu \mathrm{m}, 200 \mu \mathrm{m}, 100$ $\mu \mathrm{m}$, and $50 \mu \mathrm{m}$ mesh sieves, respectively arranged one above the other with the smallest at the bottom of the series. This operation is repeated three times with the same amount of soil.

The suspensions from the last 3 strainers $(200$ $\mu \mathrm{m}, 100 \mu \mathrm{m}$, and $50 \mu \mathrm{m})$ are each transferred separately, each into centrifuge tubes. The tubes are then centrifuged (3000 rpm) in a $70 \%$ sucrose solution at a temperature of $4^{\circ} \mathrm{C}$ for 3 minutes. The contents of each centrifuged tube are rinsed thoroughly with tap water. These contents are then distributed in petri dishes with a grid base for the observation and counting under a binocular magnifying glass of the mycorrhizal fungi spores present. Thus, the number of spores is counted in the contents of the last three grids and in each of the three replicates of soil sample considered for each site. The density of mycorrhizal fungus spores in each soil sample was determined and reported per gram of soil.

\subsubsection{Observation and estimation of mycorrhizal infection of $P$. erinaceus roots}

Root samples stored in the refrigerator after removal were washed thoroughly with water, cut into one-centimeter long fragments, and processed according to the method of Philips and Hayman [21]. They were placed in a $10 \%$ potash solution heated in a water bath $\left(80^{\circ} \mathrm{C}\right)$ for 30 minutes, and then washed thoroughly with distilled water and acidified with $1 \% \mathrm{HCl}$ for a few minutes to neutralize the $\mathrm{KOH}$ and bleach the fragments for subsequent staining. They are rinsed again with distilled water and stained with a $0.1 \%$ Trypan blue solution for 30 minutes in a water bath at $80^{\circ} \mathrm{C}$. The treated fragments were again rinsed thoroughly one last time with distilled water. A total of 30 fine root fragments from each $P$. erinaceus plant were mounted between slides in glycerol at a rate of 10 fragments per slide for microscopic examinations. Thus 120 fragments from the 4 plants from each site were observed to determine mycorrhizal structures such as hyphae, spores and vesicles [22]. The assessment of the mycorrhizal proportion of each root fragment is quantified according to the presence and abundance of mycorrhizal structures present in a fragment. The intensity and frequency of mycorrhization are determined using the scale of Trouvelot et al. [23].

\subsection{Data Analysis}

The influence of the chemical characteristics of the soil samples taken from each stand was evaluated on mycorrhization parameters (mycorrhization frequency and intensity, number of spores per gram of soil). For this purpose, redundancy analyses (RDA) were performed considering the mycorrhization and sporulation parameters in relation to the chemical characteristics of the soil of each site. Each of these RDAs was performed using the threemycorrhization parameters as response variables and the chemical characteristics of the substrates of the 5 sampling sites as posteriori explanatory environmental variables. The environmental variables are Carbon, Total Nitrogen, Carbon/Nitrogen ratio, assimilable Phosphorus, Calcium, Potassium, Sodium, 
Exchange Capacity, Electrical Conductivity, $\mathrm{PH}_{\mathrm{H} 2 \mathrm{O}}$ and $\mathrm{PH}_{\mathrm{KCl}}$ (Table 1). RDAs were performed using the "vegan" library [24] in the R version 3.6.3 statistical analysis environment [25] and the graphical outputs were obtained using the "cleanplot.pca" function [26].

The Levesne test was used to test the homogeneity of variances of mycorrhization frequencies, mycorrhization intensities and spore density per gram of the different soil samples.

An analysis of variance (ANOVA) was then performed on the dataset in order to compare the parameters between studied sites.

\section{RESULTS}

\subsection{Mycorrhization intensity and Frequency of Pterocarpus erinaceus roots}

Mycorrhizal structures such as hyphae, vesicles and spores of mycorrhizal fungi were found in the roots of $P$. erinaceus in Togo (Fig. 2). The results indicate that mycorrhization frequencies regardless of site are not significantly different $(P$ value $=0.166$ ) and range between $88 \%$ and $94 \%$. The Togodo site has the lowest mychorization frequency at $88 \%$ while the OKM and FMNP sites have the highest mychorization frequencies around 94\%. The Abdoulaye and Hahomégbé sites have respectively $93 \%$ and $89 \%$ frequency of mychorization. The intensities of mychorization are between $33.32 \%$ and $45.07 \%$ with a significant difference $(P$ value $=$ 0.001 ) of the intensity of mychorization observed at the Togodo sites $(33.52 \%)$ compared to the Abdoulaye site $(44.49 \%)$, the FMNP site $(45.07 \%)$, the Hahomégbé site $(44.22 \%)$, and the OKM site (44.55\%).

\subsection{Degree of Sporulation in the Rhizosphere of Pterocarpus Erinaceus Plants}

Spores of mycorrhizal fungi were found in soil samples collected from underneath $P$. erinaceus plants. Analysis of the results indicate a significantly higher spore density $(P$ value $=$ 0.001 ) at the two sites in the Soudanian zone, FMNP and OKM, with 16.53 spores per gram of soil and 10.66 spores per gram respectively compared to the three sites in the Guinean zone namely Abdoulaye, Hahomégbé and Togodo with 4.54 spores per gram, 3.76 spores per gram and 2.93 spores per gram of soil respectively.

Comparison of average spore densities per gram of soil indicates that there is no significant difference $(P$ value $=0.166)$ between the spore density at the FMNP and OKM sites located in the Sudanian zone. Also, no significant difference $(P$ value $=0.166)$ was noted between spore density of mycorrhizal fungi observed between the densities of the spore at the sites located in the Guinean zone, namely Abdoulaye, Hahomegbe and Togodo. However, there is a significant difference in spore densities sites located in the Guinean zone. There was also a significant difference in spore densities between the sites in the two zones (Table 2).

\subsection{Influence of Soil Chemical Components on Mycorrhization and Sporulation}

The RDA indicates that sporulation and mycorrhization intensity depend on certain soil chemical components (Fig. 2). Axis 1 of the RDA alone explains $90.64 \%$ of the relationship between substrate chemical components and mycorrhizal symbiosis in $P$. erinaceus. This axis is associated with phosphorus and nitrogen content in the soil and allows discrimination between sites in the Guinean zone (Togodo, Hahomegbe and Abdoulaye) and sites in the Sudanian domain (FMNP and OKM). Indeed, a high degree of sporulation is associated with low soil phosphorus and nitrogen content, which is characteristic of Sudanian soils, as opposed to Guinean soils. Axis 2 of the RDA explains about $9.31 \%$ of the relationships between mycorrhizal activity and substrate characteristics. It is significantly associated with mycorrhization intensity. Mycorrhization intensity is low when $\mathrm{PH}_{\mathrm{KCl}}$ is high in the substrate (Fig. 3).

The Togodo site with the highest $\mathrm{PH}_{\mathrm{KCl}}$ compared to all other sites $\left(\mathrm{PH}_{\mathrm{KC}} \mathrm{I}=5.93\right)$ recorded the lowest mycorrhization intensity $(33.52 \% \pm 2.54)$, which is significantly different from the mycorrhization intensities recorded at the Abdoulaye, FMNP, Hahomégbé and OKM sites. On the other hand, the chemical composition of the soil samples did not significantly determine the frequency of mycorrhization of $P$. erinaceus roots, although it may be associated to some extent with an increase in $\mathrm{PH}_{\mathrm{KCl}}$. 
Table 1. Chemical composition of the soil at the five identified sites

\begin{tabular}{llllll}
\hline Soil chemical characteristics & \multicolumn{2}{l}{ Study sites } & & \\
\cline { 2 - 6 } & Togodo & Abdoulaye & Hahomegbe & OKM & FMNP \\
\hline Carbon $(\mathrm{C})$ & 3.46 & 2.4198 & 2.889 & 3.035 & 2.231 \\
Total nitrogen $(\mathrm{N})$ & 2.007 & 1.403 & 1.675 & 0.123 & 0.095 \\
Ratio C/N & 18.86 & 13.92 & 19.95 & 14.293 & 13.594 \\
Assimilable Phosphorus & 3.93 & 3.21 & 3.82 & 2.81 & 2.34 \\
Calcium (Ca) & 4.003 & 2.508 & 1.992 & 3.754 & 1.791 \\
Potassium (K) & 0.48 & 0.296 & 0.204 & 0.158 & 0.188 \\
Sodium (Na) & 0.017 & 0.017 & 0.015 & 0.012 & 0.017 \\
Exchange capacity (T) & 12.97 & 19.601 & 9.926 & 12.025 & 10.646 \\
Electrical conductivity & 35 & 14 & 29 & 21 & 18 \\
$\mathrm{PH}_{\mathrm{H} 2 \mathrm{O}}$ & 6.99 & 6.11 & 6.14 & 6.29 & 5.73 \\
$\mathrm{PH}_{\mathrm{KCl}}$ & 5.93 & 5.16 & 5.30 & 5.14 & 4.58 \\
\hline
\end{tabular}

Table 2. Mycorrhization characteristics for the study sites

\begin{tabular}{llll}
\hline Study sites & $\begin{array}{l}\text { Mycorrhization } \\
\text { intensity (\%) }\end{array}$ & $\begin{array}{l}\text { Frequency of } \\
\text { mycorrhization (\%) }\end{array}$ & $\begin{array}{l}\text { Number of spores per } \\
\text { gram of soil }\end{array}$ \\
\hline Abdoulaye & $44,49 \pm 2,52^{\mathrm{a}}$ & $93,32 \pm 4,71^{\mathrm{a}}$ & $4,54 \pm 0,3^{\mathrm{b}}$ \\
FMNP & $45,07 \pm 3,27^{\mathrm{a}}$ & $94,99 \pm 4,30^{\mathrm{a}}$ & $16,53 \pm 1,25^{\mathrm{a}}$ \\
Hahomegbe & $44,22 \pm 3,07^{\mathrm{a}}$ & $88,50 \pm 1,91^{\mathrm{a}}$ & $2,93 \pm 0,43^{\mathrm{b}}$ \\
OKM & $44,55 \pm 1,91^{\mathrm{a}}$ & $94,99 \pm 4,3^{\mathrm{a}}$ & $10,66 \pm 0,71^{\mathrm{a}}$ \\
Togodo & $33,52 \pm 2,54^{\mathrm{b}}$ & $89,16 \pm 6,8^{\mathrm{a}}$ & $3,76 \pm 1,01^{\mathrm{b}}$ \\
\hline
\end{tabular}

*FMNP: Fazao-Malfakassa National Park; OKM: Oti-Keran-Mandouri national park. "a" and "b" represent the groups to which belong each site after a Tuckey Hudson test for comparison of sites' mean values for each of the 3 experienced variables

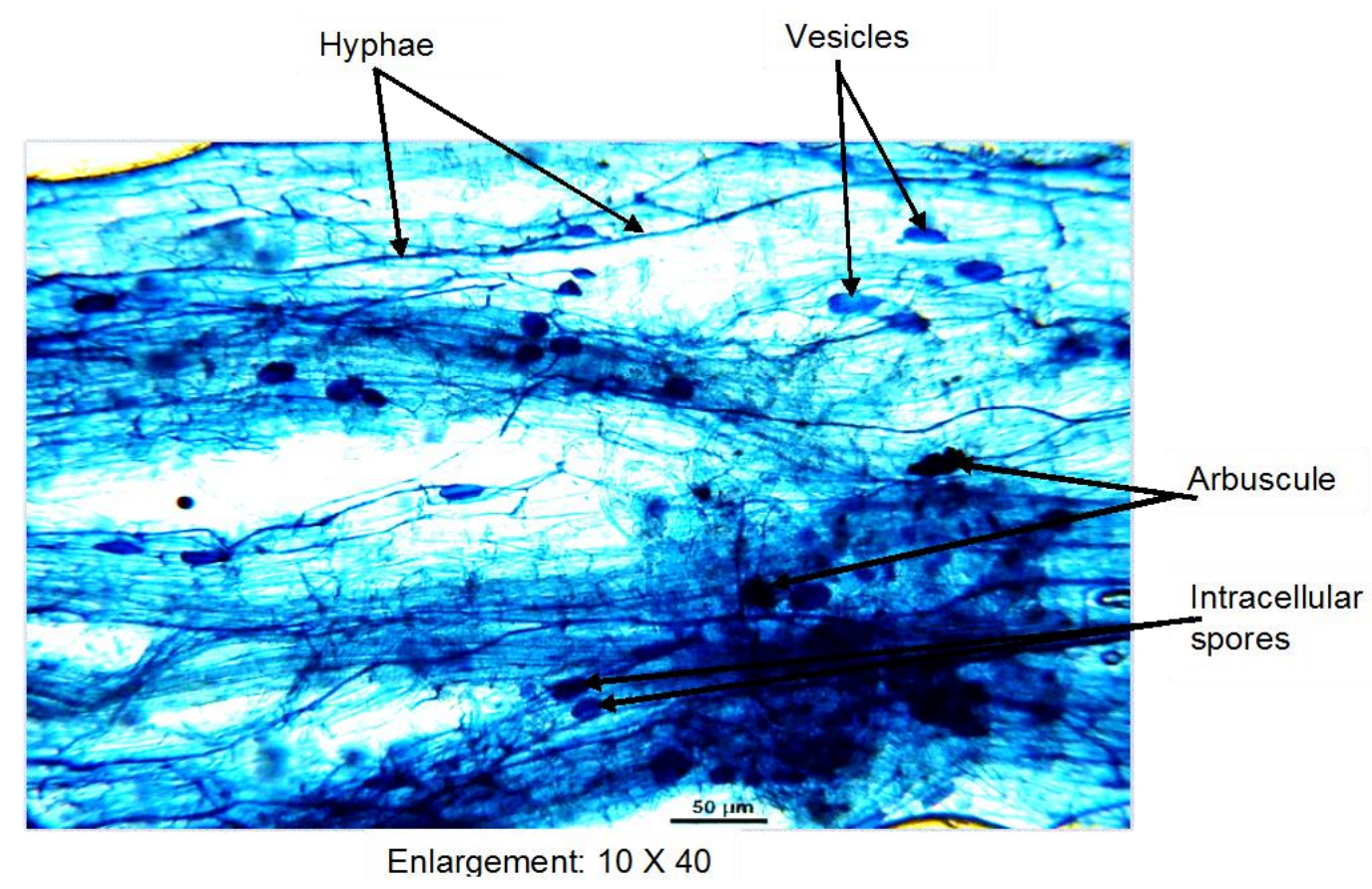

Fig. 2. Mycorrhizal structures of a root of Pterocarpus erinaceus observed by a microscope 


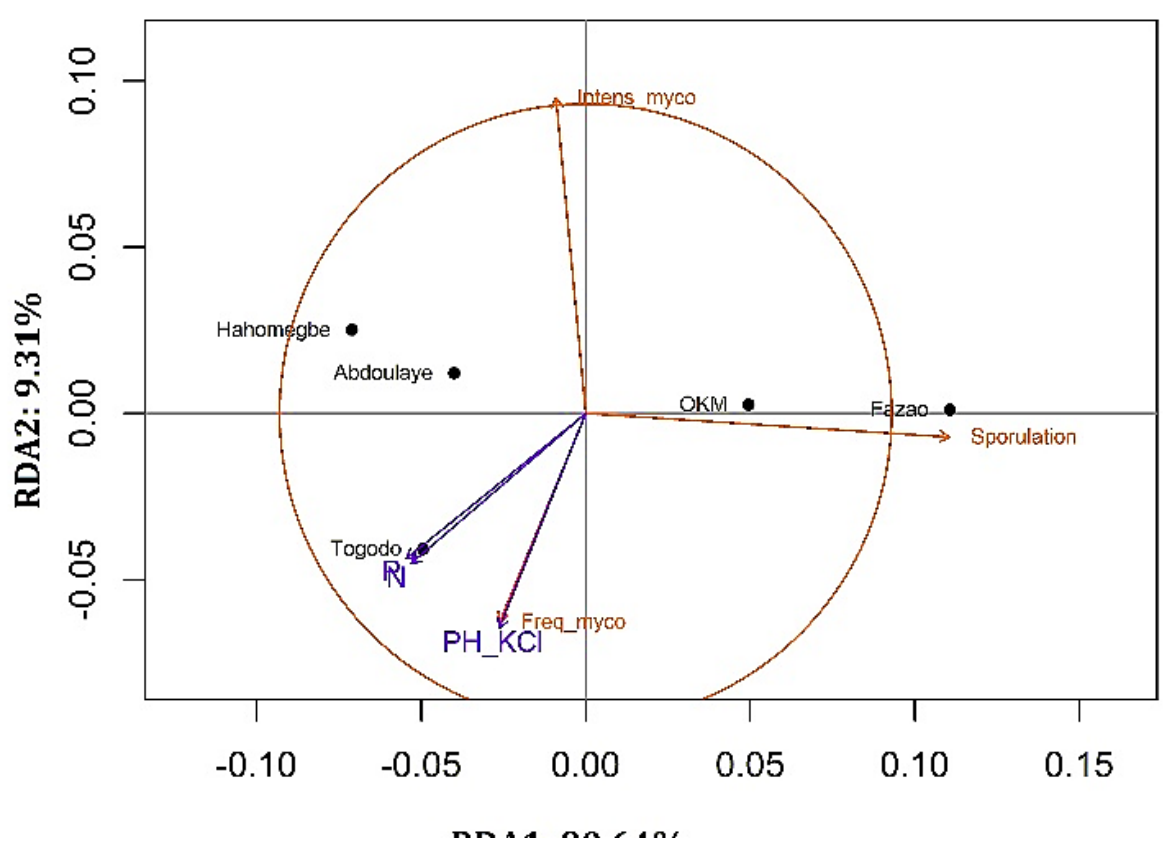

Fig. 3. Influence of soil chemical components on mycorrhization parameters

${ }^{*} F a z a o:$ Fazao-Malfakassa National Park; OKM: Oti-Keran-Mandouri national park; Freq_myco: Frequency of mycorrhization; Intens_myco: Intensity of Mycorrhization; Sporulation: Spore density per gramme of soil

\section{DISCUSSION}

The purpose of this study was to investigate the mycorrhizal status of $P$. erinaceus in order to draw lessons for its successful silviculture. The results showed that mycorrhizal structures such as vesicles, intercellular spores, arbuscules and hyphae within the root system and spores in the rhizosphere of the species in the natural environment were present at all the study sites. The presence of these structures shows that the species performs arbuscular-type endomycorrhizal symbioses similar to other tropical forest species [16,27]. However, arbuscular structures are less abundant than other mycorrhizal structures present in the roots. These results are similar to work done on Ceiba pentandra in Côte d'Ivoire [28]. Many other works have also highlighted the rarity of arbuscules among the mycorrhizal structures of many tropical forest species [16,29]. Assessment of mycorrhization frequency indicates mycorrhization frequencies that range from $88 \%$ to $94 \%$ demonstrating that $P$. erinaceus is a frequently mycorrhized species regardless of the site.

Mycorrhization intensities ranged from $33.52 \pm$ 2.54 to $45.07 \pm 3.27$ are similar to those obtained on Ceiba pentandra in Côte d'Ivoire [28]. Still, these results indicate a significant difference between the mycorrhization intensity of $P$. erinaceus roots at the Togodo site compared to the other sites. In contrast to mycorrhization frequency, mycorrhization intensity appears to be negatively correlated with increasing $\mathrm{PH}_{\mathrm{KCl}}$ in the environment. This suggests that $P$. erinaceus shows a more pronounced mycorrhizal association as the soil becomes more acidic.

The characteristics of mycorrhization frequencies $(88 \%-94 \%)$ and intensities $(33.52 \% \pm 2.54-$ $45.07 \% \pm 3.27)$ are quite high and could induce significant effects according to work done by Diagne and Ingleby [30] who revealed that beyond $12 \%$ of mycorrhization intensity, symbiotic plants benefit from this symbiotic relationship. Sporulation seems to be very important when the soil is poor in basic mineral elements such as nitrogen and phosphorus (see Fig. 2). Indeed, the spore density of mycorrhizal fungi is significantly different between the target sites in the Sudanian zone, which record $16.53 \pm$ 1.25 and $10.66 \pm 0.71$ respectively at FMNP and $\mathrm{OKM}$, and the density of the other sites located in the Guinean zone, which record lower spore densities of $2.93 \pm 0.43,3.76 \pm 1.01$, and $4.54 \pm$ 0.3 respectively for the sites at Hahomegbe, Togodo and Abdoulaye. However, spore densities taken at sites within the same climatic zone did not differ significantly from one another. This difference in sporulation could be explained 
by the specificity of environmental conditions including soil type, tree cover and climate [31].

These results on mycorrhization parameters also indicate that although there is no significant difference between the mycorrhization frequencies at the different sites, whether they are in the Sudanian (FMNP and OKM) or Guinean (Abdoulaye, Togodo and Hahomegbe) zones, spore densities seem to have higher values in the Sudanian zone. Given the characteristics of mycorrhization, early association of mycorrhizal fungi with young $P$. erinaceus seedlings from the nursery stage could be effective in the further development of the species after transplanting in the field.

\section{CONCLUSION}

This study provided evidence of mycorrhizal symbiosis in Pterocarpus erinaceus. It is clear from this study that $P$. erinaceus has a strong need for mycorrhizal symbiotic association whether in the Sudanian or Guinean zone. The obtained frequencies and intensities of mycorrhization suggest that the mycorrhizal symbiotic relationship can fundamentally determine the development of the species in its environment. The plant frequently associates with arbuscular mycorrhizal fungi regardless of its environment, but at intensities dependent on the nature or quality of the substrate. This microbial association is more pronounced when the substrate is poor in the basic mineral elements essential for the good development of terrestrial plants, namely phosphorus and nitrogen. In the Sudanian domain, the plant tends to form more pronounced symbiotic associations than in the Guinean domain.

Further studies should therefore allow an assessment of the degree of dependence of this species with respect to the possible benefits associated with this symbiosis. In a context where the domestication of this species is not yet perfected, it would be wise to isolate the species of fungi in order to study their specificity through subsequent studies. These host specificity studies should make it possible to test the adaptation of this species to biotic and abiotic conditions.

\section{ACKNOWLEDGEMENTS}

The authors are grateful to the following partners who made this research possible:
- the Economic Community of West African States (ECOWAS) through the ECOWAS Research and Innovation Support Program (PARI Program);

- the Global Climate Change Alliance (GCCA) through the Climate Change Support Program (CCSP) in Togo;

- the Southern Expert Program on Plants and Sustainable Development (SEP2D);

- the "Agence Universitaire de la Francophonie" (AUF) ;

- the "Service de Coopération et d'Action Culturelle" (SCAC) of France Embassy in Togo

- the Deutsche Gesellschaft für internationale Zusammenarbeit (GIZ) in Togo

\section{COMPETING INTERESTS}

Authors have declared that no competing interests exist.

\section{REFERENCES}

1. Alkemade $R$, Oorschot $M$ van, Miles $L$, Nellemann C, Bakkenes M, Brink B ten. GLOBIO3: A Framework to Investigate Options for Reducing Global Terrestrial Biodiversity Loss. Ecosystems. 2009;12(3): 374-390.

DOI: 10.1007/s10021-009-9229-5.

2. Arbonnier M. Arbres, arbustes et lianes des zones sèches d'Afrique de l'Ouest. 3. éd. [rev. et corr.]. Éditions Quae: Versailles ; 2009.

3. Adjonou K, Abotsi KE, Segla KN, et al. Vulnerability of African Rosewood (Pterocarpus erinaceus, Fabaceae) natural stands to climate change and implications for silviculture in West Africa. Heliyon. 2020;6(6):e04031.

DOI: 10.1016/j.heliyon.2020.e04031.

4. Solly B, Charahabil M, Dieye EB, et al. Impacts of natural and anthropogenic factors on the woody flora of HauteCasamance (south Senegal): from perception to reality. Journal of Applied Science and Environmental Studies. 2020; 3(2):117-131.

5. Rabiou H, Bationo AB, Abdou L, Segla KN, Adjonou K, Kokutse AD. Vegetative propagation by aerial layering of Pterocarpus erinaceus: In the sudanian zone. International Journal of Recent 
Advances in Multidisciplinary Research. 2017;4(10):2902-2908.

6. Segla KN, Adjonou K, Radji AR, et al. Importance socio-économique de Pterocarpus erinaceus Poir. au Togo. European Scientific Journal, ESJ. 2015; 11(23).

7. Nacoulma BMI, Traoré S, Hahn K, Thiombiano A. Impact of land use types on population structure and extent of bark and foliage harvest of Afzelia africana and Pterocarpus erinaceus in Eastern Burkina Faso. International Journal of Biodiversity and Conservation. 2011;3(3):62-72.

8. Dumenu WK, Bandoh WN. Exploitation of African Rosewood (Pterocarpus erinaceus) in Ghana: a situation analysis. Ghana J. Forestry. 2016;32:1-15.

9. Banla T, Houehanou TD, Savi MK, Idohou R, Kakaï RG, Kokou K. Population structure of Pterocarpus erinaceus Poir. across a protection gradient in Sudanian savannahs of Togo, West Africa. African Journal of Ecology. 2019;57(1):104-112. DOI: https://doi.org/10.1111/aje.12556.

10. Dumenu WK. Assessing the impact of felling/export ban and CITES designation on exploitation of African rosewood (Pterocarpus erinaceus). Biological Conservation. 2019;236:124-133.

DOI: 10.1016/j.biocon.2019.05.044.

11. Adjonou K, Towanou $\mathrm{H}$, Habou R, et al. Challenges of Conservation and Sustainable Management of African Rosewood (Pterocarpus erinaceus) in West Africa. In Natural Resources Management and Biological Sciences, Intech Open ; 2019.

12. Alaba $\mathrm{P}$, Abotsi KE, Adjonou K, Segla KN, Kokutse AD, Kokou K. Analyse des connaissances sur Pterocarpus erinaceus Poir. en Afrique Occidentale et Centrale. European Scientific Journal. 2020;16(24): 157-172.

DOI: 10.19044/esj.2020.v16n24p157.

13. Duvall C. Pterocarpus erinaceus Poir. Prota. 2008;7(1).

14. Cuny $\mathrm{P}$, Sanogo $\mathrm{S}$, Sommer N. Arbres du domaine soudanien: leurs usages et leur multiplication. Centre régional de la recherche agronomique de Sikasso ; 1997.

15. Le Tacon F, Mousain D, Garbaye J, et al. Mycorhizes, pépinières et plantations forestières en France. Revue forestière française. 1997;49:131-154.

16. Bereau M, Gazel M, Garbaye J. Les symbioses mycorhiziennes des arbres de la forêt tropicale humide de Guyane française. Canadian Journal of Botany. 1997;75(5):711-716.

17. Chen W, Meng $P$, Feng $H$, Wang $C$. Effects of Arbuscular Mycorrhizal Fungi on Growth and Physiological Performance of Catalpa bungei C.A.Mey. under Drought Stress. Forests. 2020;11(10): 1117.

DOI: $10.3390 / f 11101117$

18. Jaizme-Vega MC, Azcón R. Responses of some tropical and subtropical cultures to endomycorrhizal fungi. Mycorrhiza. 1995; 5(3):213-217.

DOI: $10.1007 / B F 00203340$.

19. Ern H. Die Vegetation Togos. Gliederung, Gefährdung, Erhaltung. Willdenowia. 1979; 9(2):295-312.

20. Gerdemann JW, Nicolson TH. Spores of mycorrhizal Endogone species extracted from soil by wet sieving and decanting. Transactions of the British Mycological society. 1963;46(2):235-244.

21. Phillips JM, Hayman DS. Improved procedures for clearing roots and staining parasitic and vesicular-arbuscular mycorrhizal fungi for rapid assessment of infection. Transactions of the British mycological Society. 1970;55(1):158-161.

22. Brundrett M, Bougher N, Dell B, Grove T, Malajczuk N. Working with mycorrhizas in forestry and agriculture. Australian Centre for International Agricultural Research Canberra; 1996.

23. Trouvelot A, Kough JL, GianinazziPearson V. Mesure du taux de mycorhization VA d'un système radiculaire. Recherche de méthode d'estimation ayant une signification fonctionnelle. In Physiological and genetical aspects of mycorrhizae: proceedings of the 1st european symposium on mycorrhizae, Dijon. 1985,1986;217-221.

24. Oksanen J, Blanchet FG, Friendly M, et al. vegan: Community Ecology Package; 2019.

25. R Core Team. R: A Language and Environment for Statistical Computing. $R$ Foundation for Statistical Computing: Vienna, Austria; 2020.

26. Borcard D, Gillet F, Legendre P. Numerical Ecology with R. 2nd ed. Springer: New York, NY; 2018.

27. Janos DP. Vesicular-Arbuscular Mycorrhizae Affect Lowland Tropical Rain Forest Plant Growth. Ecology. 1980;61(1): 151-162.

DOI: $10.2307 / 1937165$. 
28. Anguiby BLA, Ouattara G, Bomisso EL, et al. Evaluation of the mycorrhizal status of Ceiba pentandra and Tieghemella heckelii trees in the Bingerville botanical garden in Côte d'Ivoire. Journal of Applied Biosciences. 2019;138:14092-14105.

29. Onguene NA, Tsimi JPM, Balla MJE. Statut mycorhizien de l'okoumé (Aucoumea klaineana Pierre) en régénération artificielle au sud Cameroun. Tropicultura. 2002;20(3):104-108.

30. Diagne $\mathrm{O}$, Ingleby K. Ecologie des champignons mycorhiziens arbusculaires infectant Acacia raddiana. In Un arbre au désert, Acacia raddiana, Grouzis M, Le Floc'h E (eds). IRD Editions: Paris, France. 2003;205-228.

31. El Mrabet S, Msanda F, El Mousadik A, Ouahmane L. Evaluation du pouvoir mycorhizien des sols rhizosphériques de Chamaecytisus albidus et Ononis natrix dans la production de plants de qualité Argania spinosa (L.) Skeels. In Actes du 4ème Congrès International de l'Arganier, Agadir. 2017;40-48.

(C) 2021 Alaba et al.; This is an Open Access article distributed under the terms of the Creative Commons Attribution License (http://creativecommons.org/licenses/by/4.0), which permits unrestricted use, distribution, and reproduction in any medium, provided the original work is properly cited.

Peer-review history:

The peer review history for this paper can be accessed here: http://www.sdiarticle4.com/review-history/70316 